\title{
Relationship between the Concentration of Impurity and Albedo in Snow Surface
}

\author{
Yuki Komuro, Toshitaka Suzuki \\ Graduate School of Science and Engineering, Yamagata University, Yamagata, Japan \\ Email: s14e104d@st.yamagata-u.ac.jp
}

Received 25 August 2015; accepted 6 October 2015; published 9 October 2015

Copyright (C) 2015 by authors and Scientific Research Publishing Inc.

This work is licensed under the Creative Commons Attribution International License (CC BY).

http://creativecommons.org/licenses/by/4.0/

(c) (i) Open Access

\section{Abstract}

Recent decline of cryosphere typified by retreat of glaciers is often explained by temperature rise due to global warming. However, the existence of glaciers shrinking since before 1950s warming accelerated suggested that decline of cryosphere may be due to not only temperature rise, but also another possibility. As a possible cause of snow and ice melting, it has been pointed out that the surface albedo reduction due to increase of snow impurity, aeolian dust and anthropogenic pollutant, for example. To clarify the quantitative relationship between albedo and impurity in snow surface, we investigated the correlativity of turbidity and metal concentration in snow to the snow surface albedo from the simultaneous observations on the snow-covered area in Yamagata, Japan. The observed albedo shows a tendency of decrease with the turbidity increase in snow surface, we could find strong correlation between the albedo and the turbidity in $76 \%$ of contribution factor using logarithmic regression analysis. The relationship of albedo to total concentration of Fe and $\mathrm{Al}$ in snow surface shows the similar tendency to turbidity, we could model the relationship using logarithmic equation with high value of contribution ratio, $74 \%$ and $66 \%$, respectively. The concentration ratio of $\mathrm{Fe} / \mathrm{Al}$ is nearly constant with about 0.75 , which is close to mean crustal ratio of both elements, therefore, it can be said there is a strong correlation between the albedo and the concentration of mineral particle in snow surface. We cannot find a significant correlation between the albedo and total concentration of $\mathrm{Na}$ in snow surface. It can be considered that $\mathrm{Na}$ existed as dissolved ion has not significant effect to the albedo in snow surface. These results indicate that the snow albedo correlates strongly with the particulate matter in snow surface, which is typified by mineral particle.

\section{Keywords}

Snow Albedo, Snow Impurity, Mineral Particle, Metal Analysis, Acid Digestion 


\section{Introduction}

Recently, rapid decline of cryosphere typified by retreat of polar and alpine glaciers and decrease of sea ice area have attracted attention as the results of global warming problem. Characteristic white area of the cryosphere reflects most of incident solar radiation, because of the high surface albedo, the ratio of reflected radiation to incident radiation on earth's surface. Disappearing of surface snow and ice accelerate warming, and impact heavily on global weather and climate, because it enhances the absorption of solar radiation on earth's surface due to denude under covered soil and sea surface. Furthermore, it is expected that retreat of alpine glacier decrease water resource and further desertification around the glacier. The cause of cryosphere decline is often explained by the temperature rise due to global warming. However, it is reported that alpine glaciers has been shrinking since before the recent global warming [1] and the melting rate of snow and ice is inexplicable only by the temperature rise due to the grobal warming [2]. These previous studies indicate inconsistent result with the generally accepted theory, which explain the cause of snow and ice melting in recent years by the global warming.

While the albedo on snow surface (snow albedo) is generally high, approximately $80 \%-90 \%$, it is characterized by a reduction in snow albedo with the contamination of light-absorbing impurities such as soil and soot particles into the snow [3] [4]. The snow albedo reduction accelerates snow melting due to the increase of snow surface absorption of solar radiation. Additionally, the accumulation of impurity occurred by snow melting on snow surface accelerate the snow albedo reduction. In general, the increase of absorption energy on snow surface by the albedo reduction is greater than the increase of absorption energy by the atmospheric warming [2]. Therefore, the estimation of the role of albedo reduction is very important for snow and ice melting.

Separation of particle in snow using filtration method and measurement of dry weight are often used as the estimation method of impurity amount in snow [5] [6]. It has also been made an attempt to separate the organic matter from the impurities by the ignition method, and the fact is expected that most of the weight of cryoconite existing on glaciers is dominated by mineral particles [7]. However, the previous study comparing the impurity amount and albedo in snow surface from field observation data is not enough, it has not been reached that understand quantitatively the relationship between the both factors.

This study aims to clarify the quantitative relationship between albedo and impurity amount in snow surface by the simultaneous measuring on the snow-covered area in Yamagata, Japan. We measured and compared the albedo and turbidity in snow surface. Furthermore, we decompose the particulate components in snow by applying microwave acid digestion method [8], and clarify the quantitative relationship between albedo and total concentration (dissolved + particulate) of $\mathrm{Al}$, Fe and $\mathrm{Na}$ in snow surface, which become a proxy of mineral and sea salt particles.

\section{Method}

In the winter of 2010-2011, we carried out the simultaneous observations of the snow albedo measuring and surface snow sampling at the campus of the Yamagata University, located in Yamagata city, Japan. We measured surface albedo on snow using the albedometer (Hukuseflux, SRA01) in shortwave and near infrared region (305 - $2800 \mathrm{~nm}$ ). The snow albedo was calculated from the ratio of measured reflected radiation and incident radiation on snow surface. The measurements of both radiations were recoded to the data logger (HIOKI, 3645) every 2 second, and the 3 minutes average were used for the calculation of albedo on snow surface. The albedo and snow were acquired 67 times on the horizontal snow surface at the various site in the campus of the Yamagata University from 13:00 to 14:00 LT.

We scraped off the surface snow with $50 \mathrm{ml}$ centrifuge tube, collected snow sample in the tube. After the snow sample was melted at ambient temperature, we transported $10 \mathrm{ml}$ of melt water to a glass vial for turbidity measurement. The remaining sample water was used for the measurement of metal components. The turbidity in snow was measured using desktop turbidity meter (Eutech, TN-100), according to the method based on ISO7027.

For acquire the total concentration (dissolved + particulate) of metal components in snow, it is a simple and exact method that decomposes the all particulates in snow and determines the concentration of dissolved ion in decomposition solution using spectrometry. In this study, we decomposed the particulates in sample for the measurement of metal components using microwave acid digestion method [8], and then measured the total concentration of $\mathrm{Al}, \mathrm{Fe}$ and $\mathrm{Na}$ in snow using the Inductively Coupled Plasma Atomic Emission Spectrometry (ICPAES, Seiko SPS7000A). The microwave decomposition vessels (San-ai Kagaku, Type P-25), $\mathrm{HNO}_{3}$ and 
HF (Kanto Chemical Co., the Ultrapure) were used in the acid digestion experiment. Using the ICPAES, the concentration of metal components was determined by the calibration curve method with standard substance (SPEC CertiPrep, XSTC-13).

\section{Results and Discussion}

The relationship of albedo and turbidity in snow surface is shown in Figure 1. Snow albedo data shows a tendency of decrease with the turbidity increasing in snow surface. In regression analysis, contribution ratio $\left(\mathrm{R}^{2} \times\right.$ $100 \%$ ) indicate the strength of correlativity between independent variable and dependent variable. In the case of the relationship of albedo and turbidity, we obtained highest correlation by using the logarithmic regression.

Therefore, we modeled the relationship of albedo and turbidity in snow surface using logarithmic regression. It is found that there is a strong correlation between albedo and turbidity in snow surface by $76 \%$ of contribution ratio (Figure 1).

We divided the all observed data (in Figure 1) in two groups by the surface condition on snow. In Figure 2, we show the relationship of albedo and turbidity in sampling points where were not disturbed artificially, e.g. footprints and tracks. Figure 3 shows the relationship of albedo and turbidity observed in snow surface where were disturbed artificially. The data of undisturbed points was high albedo and low turbidity (Figure 2). This may be due to the observed snow surface that was not contained the dirt by human activities and kept a natural state after snowfall. In the Figure 2, the contribution ratio between the albedo and turbidity in snow surface was $56 \%$. The data observed on disturbed points was the result of low albedo and high turbidity compared to undisturbed points (Figure 3). It is possible cause that the human activities carried the dart and formed numerous

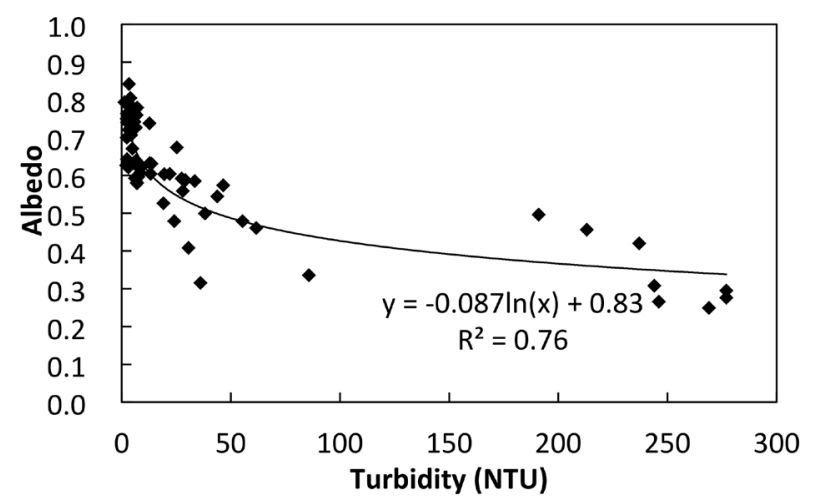

Figure 1. The albedo and turbidity in snow surface. The solid line and expression shows the regression curve and formula using logarithmic equation.

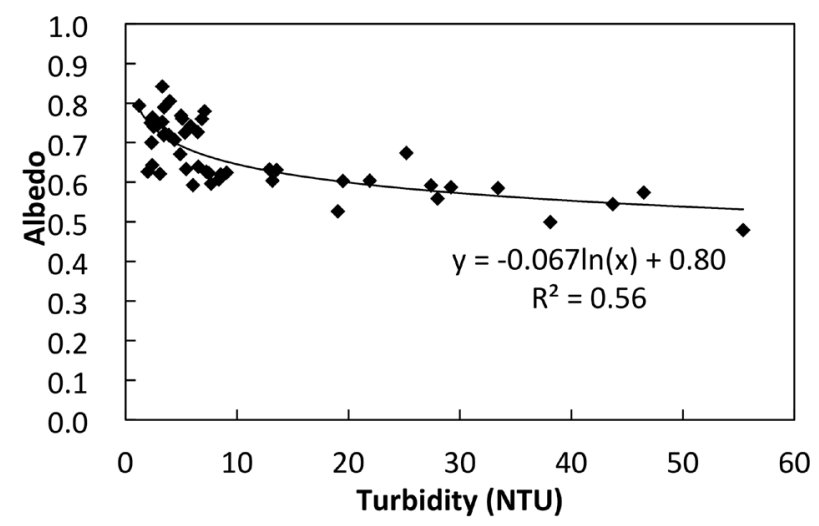

Figure 2. The albedo and turbidity in snow surface at undisturbed points. The regression curve and formula using logarithmic equation are shown as the solid line and expression. 


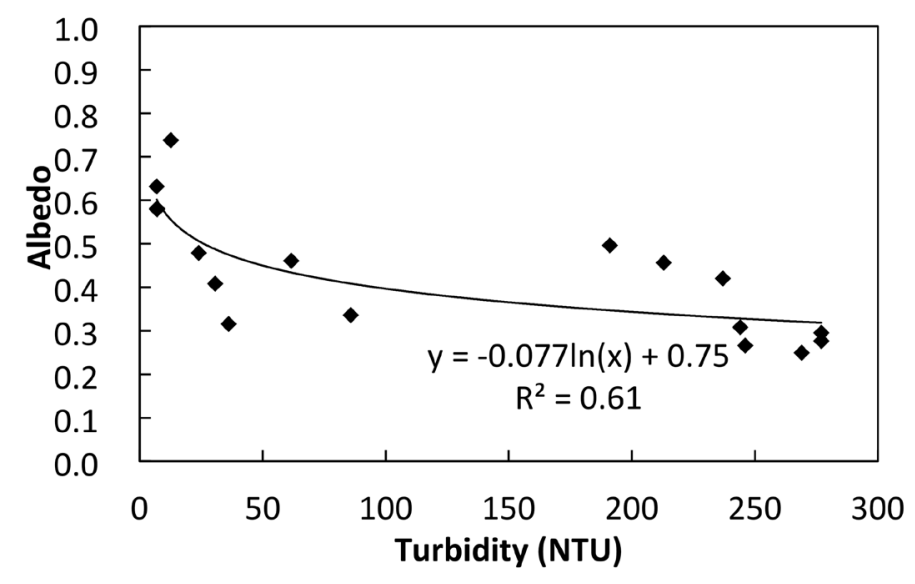

Figure 3. The albedo and turbidity in snow surface at the disturbed points. The regression curve and formula using logarithmic equation are indicated by the solid line and expression.

roughness on the snow surface, because the disturbed points are characterized by the human and vehicle movements like the parking space. The contribution ratio of albedo and turbidity in snow surface observed on disturbed points was $61 \%$.

In Figure 4 and Figure 5, we show the relationship between albedo and total concentration of $\mathrm{Fe}(\mathrm{t}-\mathrm{Fe})$ and $\mathrm{Al}$ (t-Al) in snow surface. The snow albedo decrease with t-Fe and t-Al increasing. This tendency is same of relationship between turbidity and snow albedo. As the result of comparing albedo with t-Fe and t-Al in snow surface using logarithmic regression analysis, contribution ratio became $74 \%$ and $66 \%$, we found strong correlation between the both metal concentrations and albedo.

The relationship of t-Fe and $\mathrm{t}-\mathrm{Al}$ in snow surface is shown in Figure 6. The 99\% of contribution ratio between $\mathrm{t}-\mathrm{Fe}$ and $\mathrm{t}-\mathrm{Al}$ was found by the liner regression analysis, and the ratio of concentrations was an almost constant with 0.75 . This value of concentration ratio is close to the mean crustal composition ratio of 0.68 [9], and thus indicates that most of $\mathrm{Fe}$ and $\mathrm{Al}$ in snow surface was supplied by the mineral particles, which is the crustal surface origin. Because t-Fe and t-Al correlate strongly with albedo in snow surface as showed by Figure 4 and Figure 5, it can be said there is a strong correlation between the albedo and mineral aerosol load in snow surface.

In Figure 7, we showed the relationship between albedo and total concentration of $\mathrm{Na}$ (t-Na) in snow surface. Unlike the case of $\mathrm{t}-\mathrm{Fe}$ and $\mathrm{t}-\mathrm{Al}$, there is not a particular relationship between albedo and $\mathrm{t}-\mathrm{Na}$ in snow surface. Though we performed a regression analysis using various functions, the contribution ratio of snow albedo and t-Na did not exceeds 1\%. Therefore, we divided the all observed data shown in Figure 7 to two groups, which are t-Na increasing group, the area under the broken line, and small changing group, the area over the broken line, with snow albedo decreasing, and advanced additionally the discussion removing contribution of crustal origin Na from t-Na. In Figure 8, we show the relationship between albedo and the concentration of non-crustal $\mathrm{Na}$ (ncNa) in snow surface, which removed contribution of crustal origin $\mathrm{Na}$ from $\mathrm{t}-\mathrm{Na}$. We assumed that $\mathrm{t}-\mathrm{Al}$ in snow originated entirely from crustal surface, and calculated the ncNa from the following equation:

$$
[\mathrm{ncNa}]=[\mathrm{t}-\mathrm{Na}]-(\mathrm{Na} / \mathrm{Al})_{\text {crust }} \times[\mathrm{t}-\mathrm{Al}]
$$

where $[\mathrm{t}-\mathrm{Na}]$ and $[\mathrm{t}-\mathrm{Al}]$ are the concentration of $\mathrm{t}-\mathrm{Na}$ and $\mathrm{t}-\mathrm{Al},(\mathrm{Na} / \mathrm{Al})_{\text {crust }}$ is the mean $\mathrm{Na} / \mathrm{Al}$ ratio in the crust [9], [ncNa] is the concentration of ncNa. We plotted only the data exceeded $0 \mathrm{ppm}$ of ncNa concentration in the Figure 8. Most of the data plotted in the area under the broken line in Figure 7 were not plotted in Figure 8, because the concentration of ncNa indicated less than or equal to $0 \mathrm{ppm}$. In the area under the broken line, it can be consider that most of $\mathrm{Na}$ in the snow was supplied principally by the mineral particles of crustal origin as the ncNa concentration was below $0 \mathrm{ppm}$ in despite of substantial amount of t-Na.

On the other hand, the calculated result of ncNa concentration (Figure 8) did not change nearly with the result of t-Na (Figure 7) in the area over the broken line. This result implies that the t-Na of plotted data in the area over the broken line was attributed mainly to the Na of non-crustal origin. Furthermore, it is found that the ncNa 


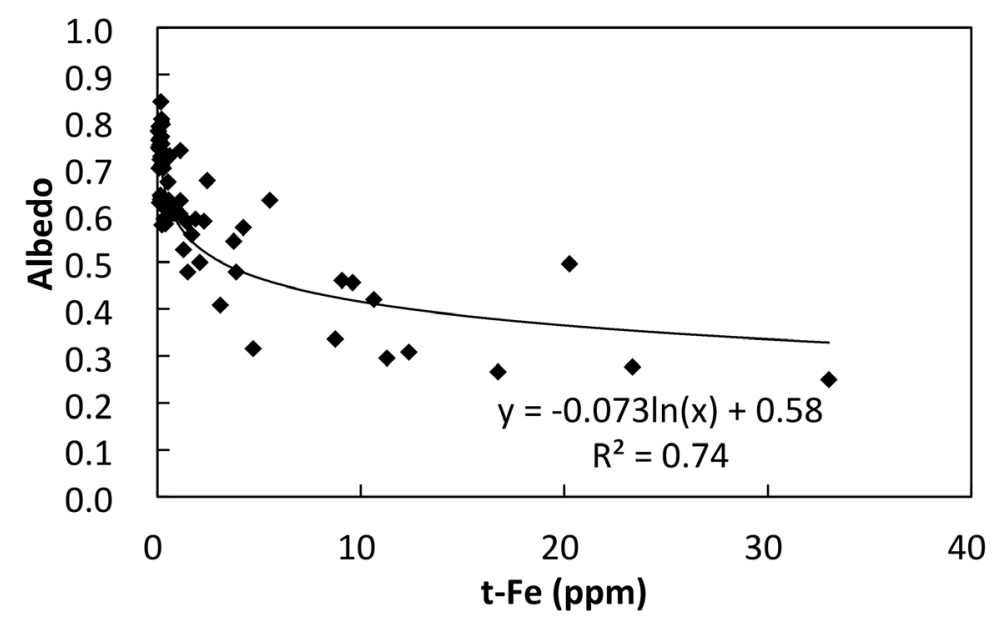

Figure 4. The albedo and t-Fe in snow surface. The solid line and expression shows the regression curve and formula by logarithmic equation.

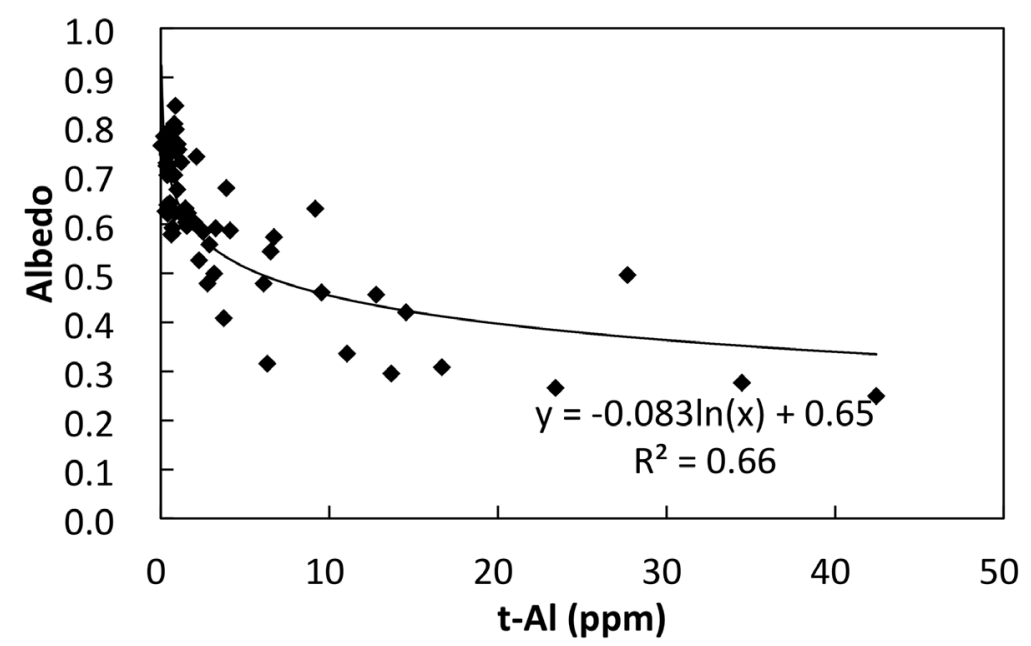

Figure 5. The albedo and t-Al in snow surface. The regression curve and formula using logarithmic equation are shown by the solid line and expression.

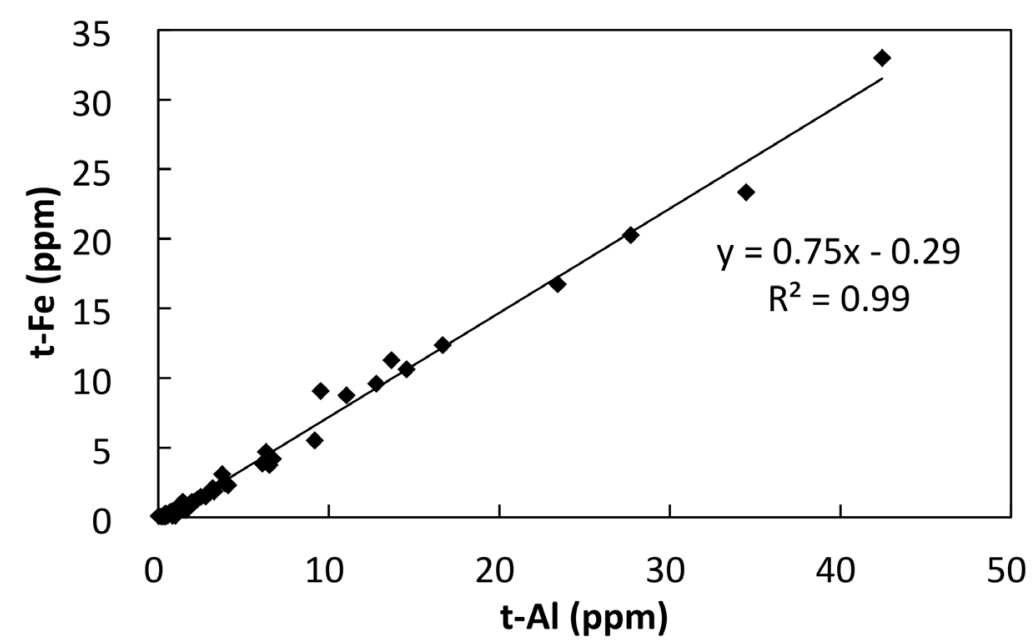

Figure 6. The t-Al and t-Fe in snow surface. The regression line and formula are shown as the solid line and expression. 


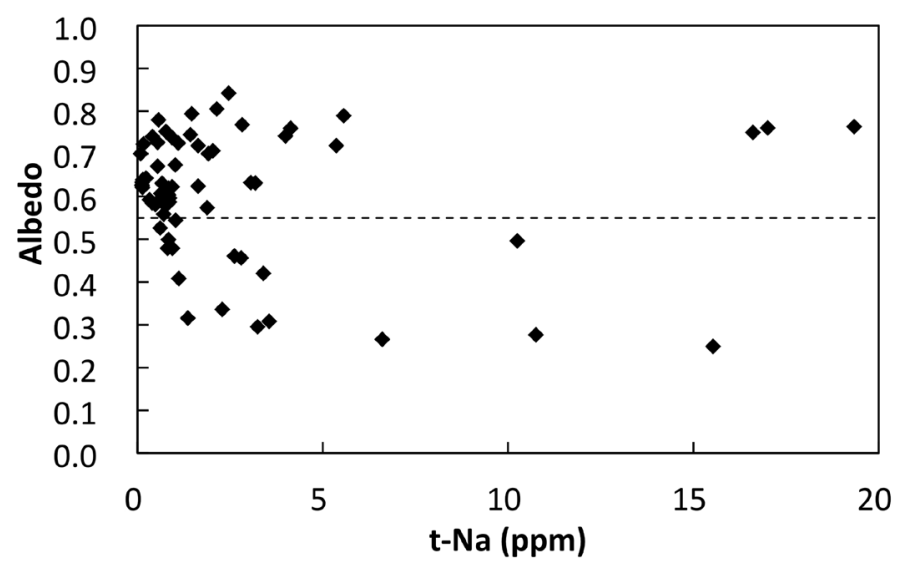

Figure 7. The albedo and t-Na in snow surface. The broken line divided the shown date to two groups, which are the t-Na increasing group and small changing group with snow albedo decreasing.

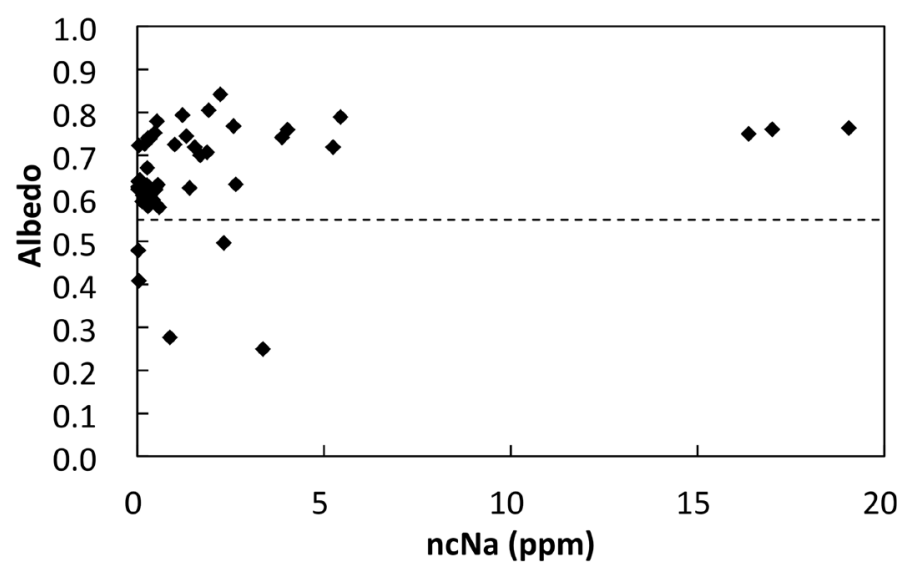

Figure 8. The albedo and ncNa in snow surface. The broken line divided the shown date to two groups, which are the ncNa increasing group and small changing group with snow albedo decreasing.

has no relationship with the albedo reduction on snow surface, because the plotted data in the area over the broken line doesn't show the tendency to point lower albedo as higher concentration of ncNa. The significant origin of the ncNa in snow may be sea salt of oceanic origin, which exists as dissolved component in snow. If the ncNa in this study is dominated largely by the sea salt $\mathrm{Na}$, it is considered that $\mathrm{Na}$ existing as dissolved ion has not significant effect on albedo reduction in snow surface. And this result suggests the possibility of bring similar results for the other dissolved components.

From the relationship between albedo and total concentration of metal components in snow surface, we showed that the particulate components as typified by mineral particles among the metal components correlate strongly with albedo in snow surface. It is expected that early and accelerated snowmelt due to the increase of mineral particle mass in snow. In the result of previous study using climate simulation [10], the albedo change with the relative variation of mineral dust flux into snow surface has a significant impact to the past ice volume change on the earth surface. By applying the metal analysis using microwave acid digestion method to the ice core samples, we can calculate selectively the mass of mineral particles in the past snow surface [11]. In the future, we can restore the change of past snow albedo by analysing the concentration of mineral particle in the ice core samples.

\section{Conclusion}

We carried out the simultaneous observations of albedo and impurity particles mass in snow surface at Yamaga- 
ta, Japan, and investigated the correlativity of turbidity and total concentration of metal components to the albedo. The observed albedo data show a tendency of decrease with the turbidity increasing in snow surface, and we could find the strong correlation of both factors with $76 \%$ of contribution ratio using the logarithmic regression analysis. As a result of comparing the albedo with t-Fe and t-Al in snow surface, we could also model the relationship of snow albedo and both concentrations using the logarithmic equation with the contribution ratio, which reached high value of $74 \%$ and $66 \%$. Additionally, the concentration ratio of t-Fe and t-Al was nearly constant at 0.75 , which was relatively close in value to the mean crustal composition ratio of 0.68 , and thus it was indicated that the albedo correlate strongly with the mineral particle mass in snow surface. There is no significant correlation between the albedo and t-Na in snow surface, because t-Na might be dominated strikingly by the sea salt and fusible $\mathrm{Na}$, we can consider that Na existing as dissolved ion has no significant effect to the albedo in snow surface. The results of this study imply that particulate components represented by mineral particles among the metal component relate especially to the albedo in snow surface. In the future, we can restore the change of past snow albedo by analysing the concentration of mineral particle in the ice core samples.

\section{Acknowledgements}

The authors thank the financial support by the ESPEC Foundation for Global Environment Research and Technology (Charitable Trust) (ESPEC Prize for the Encouragement of Environmental Studies).

\section{References}

[1] Kaser, G., Hardy, D.R., Molg, T., Bradley, R.S. and Hyera, T.M. (2004) Modern Glacier Retreat on Kilimanjaro as Evidence of Climate Change: Observation and Facts. International Journal of Climatology, 24, 329-339. http://dx.doi.org/10.1002/joc.1008

[2] Rikiishi, K. (2009) The Recent Decline of Cryosphere as Seen from the Seasonal and Decadal Changes of Snow Surface Albedo. The Symposium on Polar Meteorology and Glaciology Program and Abstracts, 32, 24.

[3] Warren, S.G. and Wiscombe, W.J. (1980) A Model for the Spectral Albedo of Snow. II : Snow Containing Atmospheric Aerosols. Journal of the Atmospheric Sciences, 37, 2734-2745. http://dx.doi.org/10.1175/1520-0469(1980)037<2734:AMFTSA>2.0.CO;2

[4] Dumont, M., Brun, E., Picard, G., Michou, M., Libois, Q., Petit, J.-R., Geyer, M., Morin, S. and Josse, B. (2014) Contribution of Light-Absorbing Impurities in Snow to Greenland's Darkening since 2009. Nature Geoscience, 7, 509-512. http://dx.doi.org/10.1038/ngeo2180

[5] Motoyoshi, H., Aoki, T., Hori, M., Abe, O. and Mochizuki, M. (2005) Possible Effect of Anthropogenic Aerosol Deposition on Snow Albedo Reduction at Shinjo, Japan. Journal of the Meteorological Society of Japan, 83A, 137-148. http://dx.doi.org/10.2151/jmsj.83A.137

[6] Aoki, T., Motoyoshi, H., Kodama, Y., Yasunari, T.J., Sugiura, K. and Kobayashi, H. (2006) Atmospheric Aerosol Deposition on Snow Surfaces and Its Effect on Albedo. SOLA, 2, 13-16. http://dx.doi.org/10.2151/sola.2006-004

[7] Takeuchi, N., Matsuda, Y., Sakai, A. and Fujita, K. (2005) A Large Amount of Biogenic Surface Dust (Cryoconite) on a Glacier in the Qilian Mountains, China. Bulletin of Glaciological Research, 22, 1-8.

[8] Suzuki, T. and Sensui, M. (1991) Application of the Microwave Acid Digestion Method to the Decomposition of Rock Samples. Analytica Chimica Acta, 245, 43-48. http://dx.doi.org/10.1016/S0003-2670(00)80199-3

[9] Taylor, S.R. (1964) Abundance of Chemical Elements in the Continental Crust: A New Table. Geochimica et Cosmochimica Acta, 28, 1273-1285. http://dx.doi.org/10.1016/0016-7037(64)90129-2

[10] Bar-Or, R., Erlick, C. and Gildor, H. (2008) The Role of Dust in Glacial-Interglacial Cycles. Quaternary Science Reviews, 27, 201-208. http://dx.doi.org/10.1016/j.quascirev.2007.10.015

[11] Sato, H., Suzuki, T., Hirabayashi, M., Iizuka, Y., Motoyama, H. and Fujii, Y. (2013) Mineral and Sea-Salt Aerosol Fluxes over the Last 340 kyr Reconstructed from the Total Concentration of $\mathrm{Al}$ and Na in the Dome Fuji Ice Core. Atmospheric and Climate Sciences, 3, 186-192. 